\title{
Germline CHEK2 mutations and colorectal cancer risk: different effects of a missense and truncating mutations?
}

Cezary Cybulski $^{*, 1}$, Dominika Wokołorczyk ${ }^{1}$, Józef Kładny ${ }^{1}$, Grzegorz Kurzwaski ${ }^{1}$, Joanna Suchy ${ }^{1}$, Ewa Grabowska ${ }^{1}$, Jacek Gronwald ${ }^{1}$, Tomasz Huzarski ${ }^{1}$, Tomasz Byrski ${ }^{1}$, Bohdan Górski ${ }^{1}$, Tadeusz Dȩbniak ${ }^{1,2}$, Steven A Narod ${ }^{2}$ and Jan Lubiński ${ }^{1}$

\footnotetext{
${ }^{1}$ Pomeranian Medical University, Szczecin, Poland; ${ }^{2}$ Centre for Research on Womens Health, University of Toronto, Toronto, Ontario
}

Germline mutations in cell cycle checkpoint kinase 2 (CHEK2) have been associated with a range of cancer types, in particular of the breast and prostate. Protein-truncating mutations in CHEK2 have been reported to confer higher risks of cancer of the breast and the prostate than the missense I157T variant. In order to estimate the risks of colorectal cancer associated with truncating and missense CHEK2 mutations, we genotyped 1085 unselected colorectal cancer cases and 5496 controls for four CHEK2 founder mutations present in Poland. We observed an increased risk of colorectal cancer in association with the missense I157T mutation (odds ratios $(\mathrm{OR})=1.5 ; 95 \% \mathrm{Cl} 1.2-2.0 ; P=0.002$ ) but not with truncating mutations $(\mathrm{OR}=1.0 ; 95 \% \mathrm{Cl} 0.5-1.8 ; P=0.9) ;$ however the difference in the two $\mathrm{OR}$ was not statistically significant $(P=0.2)$. We conclude that the I157T mutation increases the risk of colorectal cancer in the population, but that truncating mutations may confer a lower risk or no increase in risk. It is important that other studies of CHEK2 mutation carriers be conducted to confirm this hypothesis.

European Journal of Human Genetics (2007) 15, 237-241. doi:10.1038/sj.ejhg.5201734; published online 15 November 2006

Keywords: colon cancer; CHEK2 gene; CHK2 gene; germline mutations; hereditary; susceptibility

\section{Introduction}

Cell cycle checkpoint kinase 2 (CHEK2) is a key component of the DNA damage pathway. Activation of this protein in response to DNA mutation prevents cellular entry into mitosis. ${ }^{1,2}$ Germline mutations in CHEK2 have been associated with a range of cancer types, in particular of the breast and the prostate. ${ }^{3-23}$ The majority of predisposing CHEK2 alleles are protein-truncating, but a missense variant (I157T) has also been associated with cancer at various sites. ${ }^{9}$

*Correspondence: Dr C Cybulski, Department of Genetics and Pathology, International Hereditary Cancer Center, Pomeranian Medical University, ul. Połabska 4, Szczecin 70-115, Poland.

Tel: + 4891466 1532; Fax: + 4891466 1533;

E-mail: cezarycy@sci.pam.szczecin.pl

Received 5 July 2006; revised 13 September 2006; accepted 6 October 2006; published online 15 November 2006
Four CHEK2 mutations are founder alleles in Poland. Three of these are protein-truncating (del5395, IVS $2+1 \mathrm{G}>\mathrm{A}, 1100 \mathrm{delC})$ and the other is a common missense variant I157T. Previously, we genotyped 300 Polish patients with colorectal cancer and 4000 controls for three common CHEK2 mutations. ${ }^{9}$ We have now extended our series to include 1085 incident cases of colon cancer and 5496 controls, and we have genotyped these for the four CHEK2 founder mutations that are present in the population.

Materials and methods

Patients

We studied 1085 colorectal cancer cases diagnosed between 1998 and 2005 in three centres in North-Western Poland. 964 colon cancer cases were diagnosed in Szczecin between 
1998 and 2005 and 121 cases were diagnosed in Koszalin and Kołobrzeg between 2003 and 2005. Patients were recruited from the six contributing hospitals in these cities and were unselected for age and family history. All men and women with colorectal cancer were invited to participate. The participation rate exceeded $80 \%$. The mean age of diagnosis was 63.1 years (range 21-92 years). A family history of colorectal cancer in relatives was available from all subjects. One hundred and ten cases $(10.1 \%)$ had a first-degree relatives diagnosed with colon cancer (familial cases). The study was approved by the Ethics Committee of Pomeranian Medical University in Szczecin.

\section{Controls}

In order to estimate the frequency of the Polish founder mutations in the general population, three control groups were combined. The first group consisted of 2183 newborn children from 9 cities throughout Poland (Szczecin, Białystok, Gorzów, Katowice, Wrocław, Poznań, Opole, Łódź and Rzeszów) between 2003 and 2006. Samples of cord blood from unselected infants were forwarded to the study centre in Szczecin. The second control group was taken from healthy adult patients (1079 women and 817 men) of three family doctors practicing in the Szczecin region. These individuals were selected randomly from the patient lists of family doctors. The third control group consisted of 1417 young adults (705 women and 712 men) from Szczecin who submitted blood for paternity testing.

\section{Genotyping}

Two primer pairs were used for genotyping of large deletion of exon 9 and 10 in multiplex-PCR reaction as previously described. ${ }^{22}$ The first pair flanked breakpoint site in intron 8 and the second pair flanked breakpoint site in intron 10 . In mutation-negative cases, only two PCR fragments of 379 and $522 \mathrm{bp}$ were amplified from the wild-type allele. In deletion-positive cases, the forward primer of the first pair and the reverse primer of the second pair amplified additional PCR product of $450 \mathrm{bp}$.

All-deletion positive cases were confirmed by sequencing. The other three mutations in CHEK2 (IVS2 + 1G $>\mathrm{A}$, 1100delC and I157T) were genotyped as previously described. ${ }^{9}$ These variants are detected by ASO- or RFLPPCR analyses. In all reaction sets, positive and negative controls (without DNA) were used. All PCR reactions or enzymatic digestions were performed under a layer of mineral oil.

All four CHEK2 alleles present in Poland are in the functional copy of CHEK2 gene at chromosome 22 (not in pseudogenes located elsewhere). ${ }^{9,20,22}$

\section{Statistical analysis}

The prevalence of each of the three CHEK2 alleles in cases and in population controls was compared. ORs were generated from two-by-two tables and statistical significance was assessed using the $\chi^{2}$ test. The ORs were used as estimates of relative risk.

\section{Results}

One of four founder CHEK2 mutations was identified in 87 of 1085 subjects with colorectal cancer (8.0\%), including I157T (77 times), 1100delC (five times), del5395 deletion (four times) and IVS $2+1 \mathrm{G}>\mathrm{A}$ (two times). The OR for colorectal cancer, given a CHEK2 missense mutation (I157T) was 1.5 (95\% CI1.2-2.0; $P=0.002)$ (Table 1). The I157T variant was seen in $10 \%$ of familial cases $(\mathrm{OR}=2.2$, $95 \%$ CI $1.2-4.1 ; P=0.01)$. In contrast, we saw no association between CHEK2 truncating alleles and colorectal cancer risk $(\mathrm{OR}=1.0 ; 95 \% \mathrm{CI} 0.5-1.8 ; P=0.9)$. A test for homogeneity of OR was conducted, but we were unable to reject the null hypothesis that both ORs are from the same underlying distribution $(P=0.2)$.

The mean age of diagnosis of colon cancer in mutation non-carriers was 63.3. The mean age of diagnosis of carriers of a CHEK2 missense mutation was 61.8 years $(P=0.3$ for difference).

\section{Discussion}

We studied four CHEK2 alleles in relation to colon cancer risk in Poland. We saw a modest but significantly increased risk of colon cancer associated with the I157T variant $(\mathrm{OR}=1.5, \quad P=0.002)$. The association was particularly strong in the subgroup of patients with familial colon cancer (OR 2.2, $P=0.01$ ) but this subgroup was small (110 cases). A predisposing I157T mutation in CHEK2 was present in $7 \%$ of Polish colon cancer patients. On average, individuals who carry this mutation have a 1.5 -fold increased risk of colon cancer risk. We estimate that this particular CHEK2 allele is responsible for approximately $3 \%$ of all colon cancer cases in the country.

There was no association between the allele frequencies and either age or sex in our control population. The frequency of a CHEK2 mutation was $6.0 \%$ in 1529 adult men $(5.0 \%$ for the $157 \mathrm{~T}$ and $1.0 \%$ for a truncating variant) and $5.8 \%$ in 1784 adult women $(4.9 \%$ for the $1157 \mathrm{~T}$ and $0.9 \%$ for a truncating variant) The frequency was $5.8 \%$ in 2183 newborns $(4.6 \%$ for the I157T and $1.2 \%$ for a truncating variant), 5.6\% in 1417 young adults who submitted blood for paternity testing (4.8\% for the I157T and $0.8 \%$ for a truncating variant), and $6.0 \%$ in 1896 adult patients from family doctors $(5.0 \%$ for the I157T and $1.0 \%$ for a truncating variant) (Table 2 ).

Previously, we genotyped 300 individuals with colorectal cancer and 4000 controls. ${ }^{9}$ We have extended our series to include an additional 785 cases and 1496 controls. In the initial sample, the I157T variant was seen in $9.3 \%$ of cases 
Table 1 Prevalence of CHEK2 mutations in cases and controls with corresponding odds ratios

\begin{tabular}{lccr}
\hline Mutation subjects & No. of carriers/total (frequency) & OR & $95 \% \mathrm{Cl}$ P-value \\
\hline A truncating mutation ${ }^{\mathrm{a}}$ & & & \\
$\quad$ Controls & $58 / 5496(1.1 \%)$ & 1.0 & $0.5-1.8$ \\
Unselected cases & $11 / 1085(1.0 \%)$ & 1.7 & $0.4-7.2$ \\
Familial cases & $2 / 110(1.8 \%)$ & & 0.44 \\
$1157 T$ & & 1.0 & $1.2-2.0$ \\
Controls & $264 / 5496(4.8 \%)$ & 1.5 & 0.002 \\
Unselected cases & $77 / 1085(7.1 \%)$ & 2.2 & 0.01 \\
Familial cases & $11 / 110(10 \%)$ & & \\
\hline
\end{tabular}

One case and one control had both truncating and missense mutations.

${ }^{a} \mathrm{~A}$ truncating mutation - del5395 or IVS2 $+1 \mathrm{C}>\mathrm{A}$ or $1100 \mathrm{delC}$.

Table 2 Frequencies of CHEK2 variant alleles in adult and newborn controls

\begin{tabular}{lcccc}
\hline & & & Variant & \\
& del5395 & IVS2+1G $>A$ & 1100delC & I157T \\
\hline Newborns $(n=2183)$ & $11(0.50 \%)$ & $10(0.46 \%)$ & $5(0.23 \%)$ & $101(4.6 \%)$ \\
Adults $(n=3313)$ & $13(0.39 \%)$ & $12(0.36 \%)$ & $7(0.21 \%)$ & $163(4.9 \%)$ \\
\hline
\end{tabular}

versus $4.8 \%$ of controls $(\mathrm{OR}=2.0 ; \quad P=0.001)$, and a truncating mutation was seen in $1.3 \%$ of cases versus $1.1 \%$ of controls $(\mathrm{OR}=1.2 ; P=0.7)$. In the additional series, the I157T was present in $6.2 \%$ of cases versus $4.7 \%$ of controls $(\mathrm{OR}=1.3 ; P=0.1)$, and a truncating mutation was present in $0.9 \%$ of cases and controls, respectively, ( $\mathrm{OR}=1.0 ; P=0.9)$. Although the association in the second sample was less strong than that seen in the original report, in the combined sample the statistical significance was maintained $(P=0.002)$.

Our results are in agreement with those of a recent study from Finland, ${ }^{19}$ wherein the frequency of I157T variant was higher in colorectal cancer patients $(7.8 \%, 76 / 972)$ than in population controls $(5.3 \%, 100 / 1885)(\mathrm{OR}=1.5$, $95 \% \mathrm{CI}=1.1-2.1, P=0.008)$. In that study, the I157T was also found to be associated more strongly with familial cases $(\mathrm{OR}=2.1, P=0.01)$. The frequencies of the $\mathrm{I} 157 \mathrm{~T}$ mutation are similar in Poland and Finland (4.8 and 5.3\%) and the corresponding ORs are almost identical. Combining the data from the Finnish and Polish studies yields an overall OR of 1.5 (95\% CI: $1.3-1.9, P<0.0001)$, thus confirming that CHEK2 is pathogenic for colorectal cancer.

It was initially suggested that the CHEK2 1100delC mutation was associated with colorectal cancer; the prevalence of CHEK2 1100delC was observed to be higher in breast cancer families with colorectal cancer than in families without colorectal cancer. ${ }^{14}$ To date, this result has not been confirmed. ${ }^{24}$ Two recent studies investigated the frequency of CHEK2 1100delC in unselected colorectal cancer cases and controls. ${ }^{25,26}$ In Finland, the 1100delC mutation was not associated with increased colorectal cancer risk - the 1100delC allele was detected in $2.6 \%$ (17/662) of cases and $1.9 \%$ of 1885 controls. ${ }^{24}$ A study from the Netherlands reported a trend towards a higher frequency of the 1100delC mutation in 629 unselected colorectal cancer cases than in 230 controls (1.6 versus $0.4 \%, \mathrm{OR}=3.7 ; P=0.3),{ }^{25}$ but in that study there was only one carrier of the $1100 \mathrm{delC}$ in the control group. In the UK, the CHEK2 1100delC allele was not seen in excess in 149 patients with multiple colorectal adenomas (some of whom developed colorectal cancer). ${ }^{26}$

We did not see an association between any CHEK2 truncating mutation and colorectal cancer risk in Poland $(\mathrm{OR}=1.0 ; P=0.95)$. A truncating variant was seen in $1.0 \%$ of the colon cancer patients. This contrasts strongly with our recent observations that a truncating variant was present in $2.4 \%$ of prostate cancer patients ${ }^{22}$ and in $2.5 \%$ of unselected breast cancer patients. ${ }^{23}$ Based on a study of 1085 cases and 5496 controls, and a frequency in controls of truncating mutations of $1.1 \%$, we had a power of $76 \%$ to detect a relative risk of 2.0 associated with truncating mutations, and a power of $36 \%$ to detect a relative risk of 1.5 (at the $P=0.05$ level). Also, our study had limited power to provide evidence for heterogeneity between the missense mutation and the truncating mutations - however, together with the previous reports the aggregate data support the hypothesis that the I157T mutation confer increased colorectal cancer risk, and that truncating CHEK2 mutations may confer a lower risk or no elevated risk.

CHEK2 is involved in the p53 pathway of DNA damage responses. CHEK2 interacts with many different proteins. Upon ionizing radiation-induced DNA damage, CHEK2 is 
activated by ataxia telangiectasia mutated (ATM) and is in turn capable of phosphorylating several substrates including Cdc25A, Cdc25C, p53, and BRCA1, leading to cell cycle arrest, apoptosis and DNA repair (reviewed $\mathrm{in}^{27}$ ).

The protein with I157T variant is stable. The I157T missense variant is localized in a functionally important domain of CHEK2 (the FHA domain) and protein with this mutation has been shown to be defective in its ability to bind and to phosphorylate Cdc25A and to bind p53 and BRCA1. ${ }^{28-30}$ The I157T protein may also have a dominantnegative effect by forming heterodimers with wild-type CHEK2. ${ }^{10}$ A dominant negative-effect was shown to influence clinical presentation. For example, tumours that develop in heterozygous carriers of an ATM mutation gene (the gene in the same pathway as CHEK2) appear to be the consequence of a dominant-negative effect of the ATM protein, whereas heterozygous carriers of ATM truncating mutations do not seem to be at an increased cancer risk. ${ }^{31,32}$ Similarly, only specific missense mutations, which cause local protein defects, confer high-risk of pheochromocytoma in VHL diesease, whereas typically VHL patients with truncating mutations do not develop pheochromocytoma. ${ }^{33,34}$ Therefore, in theory, if a dominant negativeeffect of CHEK2 protein is present the effects of CHEK2 truncating and missense mutations might be different.

In conclusion, there are four variant founder alleles of the CHEK2 gene in Poland. Of these, only the I157T was seen in significant excess in Polish patients with colorectal cancer. It is possible that there is a variation in the risks of cancers associated with CHEK2 mutations, depending on the class of mutation studied. If present, such genotypephenotype correlation might be due to a possible dominant-negative effect of the I157T variant. It is important that other studies of CHEK2 mutation carriers be conducted to verify this hypothesis.

\section{References}

1 Matsuoka S, Rotman G, Ogawa A, Shiloh Y, Tamai K, Elledge SJ: Ataxia telangiectasia-mutated phosphorylates Chk2 in vivo and in vitro. Proc Natl Acad Sci USA 2000; 97: 10389-10394.

2 Chaturvedi P, Eng WK, Zhu Y et al: Mammalian Chk2 is a downstream effector of the ATM-dependent DNA damage checkpoint pathway. Oncogene 1999; 18: 4047-4054.

3 Bell DW, Varley JM, Szydlo TE et al: Heterozygous germ line hCHK2 mutations in Li-Fraumeni syndrome. Science 1999; 286: $2528-2531$.

4 Vahteristo P, Tamminen A, Karvinen P et al: p53, CHK2, and CHK1 genes in Finnish families with $\mathrm{Li}$-Fraumeni syndrome: further evidence of CHK2 in inherited cancer predisposition. Cancer Res 2001; 61: 5718-5722.

5 CHEK2 Breast Cancer Consortium: Low-penetrance susceptibility to breast cancer due to CHEK2* 1100 delC in noncarriers of BRCA1 or BRCA2 mutations. Nat Genet 2002; 31: 55-59.

6 Oldenburg RA, Kroeze-Jansema K, Kraan J et al: The CHEK2*1100delC variant acts as a breast cancer risk modifier in nonBRCA1/BRCA2 multiple-case families. Cancer Res 2003; 63: $8153-8157$.
7 Vahteristo P, Bartkova J, Eerola $\mathrm{H}$ et al: A CHEK2 genetic variant contributing to a substantial fraction of familial breast cancer. Am J Hum Genet 2002; 71: 432-438.

8 CHEK2 Breast Cancer Case-Control consortium: CHEK2*1100delC and susceptibility to breast cancer: a collaborative analysis involving 10,860 breast cancer cases and 9,065 controls from 10 studies. Am J Hum Genet 2004; 74: 1175-1182.

9 Cybulski C, Gorski B, Huzarski T et al: CHEK2 is a multiorgan cancer susceptibility gene. Am J Hum Genet 2004; 75: $1131-1135$

10 Kilpivaara O, Vahteristo P, Falck J et al: CHEK2 variant I157 may be associated with increased breast cancer risk. Int J Cancer 2004; 111: $543-547$.

11 Shaag A, Walsh T, Renbaum P et al: CHEK2 allele associated with breast cancer in the Ashkenazi Jewish population. Hum Mol Genet 2005; 14: 555-563.

12 Cybulski C, Huzarski T, Górski B et al: A novel founder CHEK2 mutation is associated with increased prostate cancer risk. Cancer Res 2004; 64: 2677-2679.

13 Dong X, Wang L, Taniguchi $\mathrm{K}$ et al: Mutations in CHEK2 associated with prostate cancer risk. Am J Hum Genet 2003; 72: $270-280$.

14 Meijers-Heijboer H, Wijnen J, Vasen $\mathrm{H}$ et al: The CHEK2 1100delC mutation identifies families with a hereditary breast and colorectal cancer phenotype. Am J Hum Genet 2003; 72: $1308-1314$

15 Allinen M, Huusko P, Mantyniemi S, Launonen V, Winqvist R: Mutation analysis of the CHK2 gene in families with hereditary breast cancer. Br J Cancer 2001; 85: 209-212.

16 Schutte M, Seal S, Barfoot R et al: Variants in CHEK2 other than 1100delC do not make a major contribution to breast cancer susceptibility. Am I Hum Genet 2003; 72: 1023-1028.

17 Bogdanova N, Enssen-Dubrowinskaja N, Feshchenko S et al: ssociation of two mutations in the CHEK2 gene with breast cancer. Int J Cancer 2005; 116: 263-266.

18 Seppala EH, Ikonen T, Mononen N et al: CHEK2 variants associate with hereditary prostate cancer. Br J Cancer 2003; 89: 1966-1970.

19 Kilpivaara O, Alhopuro P, Vahteristo P, Aaltonen LA, Nevanlinna H: CHEK2 I157T associates with familial and sporadic colorectal cancer. J Med Genet 2006; 43: e34.

20 Rudd MF, Sellick GS, Webb EL, Catovsky D, Houlston RS: Variants in the ATM-BRCA2-CHEK2 axis predispose to chronic lymphocytic leukaemia. Blood 2006, in press.

21 Walsh T, Casadei S, Coats $\mathrm{KH}$ et al: Spectrum of mutations in BRCA1, BRCA2, CHEK2, and TP53 in families at high risk of breast cancer. JAMA 2006; 295: 1379-1388.

22 Cybulski C, Wokołorczyk D, Huzarski T et al: A large germline deletion in CHEK2 is associated with an increased risk of prostate cancer. J Med Genet 2003, in press.

23 Cybulski C, Wokołorczyk D, Huzarski T et al: A deletion in CHEK2 of 5395 basepairs predisposes to breast cancer in poland. Breast Cancer Res Treat 2006, in press.

24 Kilpivaara O, Laiho P, Aaltonen LA, Nevanlinna H: CHEK2 1100delC and colorectal cancer. J Med Genet 2003; 40: e110.

25 de Jong MM, Nolte IM, Te Meerman GJ et al: Colorectal cancer and the CHEK2 1100delC mutation. Genes Chromosomes Cancer 2005; 43: 377-382.

26 Lipton L, Fleischmann C, Sieber OM, Thomas HJ, Hodgson SV, Tomlinson IP et al: Contribution of the CHEK2 1100delC variant to risk of multiple colorectal adenoma and carcinoma. Cancer Lett 2003; 200: 149-152.

27 Bartek J, Lukas J: Chk1 and Chk2 kinases in checkpoint control and cancer. Cancer Cell 2003; 3: 421-429.

28 Falck J, Lukas C, Protopopova M, Lukas J, Selinanova G, Bartek J: Functional impact on concomitant versus alternative defects in the Chk2-p53 tumour suppressor pathway. Oncogene 2001; 20: $5503-5510$.

29 Falck J, Mailand N, Syljuåsen RG, Bartek J, Lukas J: The ATMChk2-Cdc25A checkpoint pathway guards against radioresistant DNA synthesis. Nature 2001; 410: 842-847. 
$30 \mathrm{Li}$ J, Williams BL, Haire LF et al: Structural and functional versatility of the FHA domain in DNA-damage signaling by the tumor suppressor kinase Chk2. Mol Cell 2002; 9: 1045-1054.

31 Spring K, Ahangari F, Scott SP et al: Mice heterozygous for mutation in Atm, the gene involved in ataxia-telangiectasia, have heightened susceptibility to cancer. Nat Genet 2002; 32: $185-190$.

32 Scott SP, Bendix R, Chen P, Clark R, Dork T, Lavin MF: Missense mutations but not allelic variants alter the function of ATM by dominant interference in patients with breast cancer. Proc Nat Acad Sci USA 2002; 99: 925-930.

33 Crossey PA, Richards FM, Foster $\mathrm{K}$ et al: Identification of intragenic mutations in the von Hippel-Lindau disease tumour suppressor gene and correlation with disease phenotype. Hum Mol Genet 1994; 3: 1303-1308.

34 Chen F, Kishida T, Yao M et al: Germline mutations in the von Hippel-Lindau disease tumor suppressor gene: correlations with phenotype. Hum Mutat 1995; 5: 66-75. 